\title{
Opas turvalliseen karjanhoitoon
}

\author{
Marja Kallioniemi $^{1)}$ ja Hanna-Riitta Kymäläinen ${ }^{2)}$ \\ ${ }^{1)}$ Luonnonvarakeskus, Talous ja yhteiskunta,Vakolantie 55,03400Vihti,marja.kallioniemi@luke.fi \\ 2) \\ Helsingin yliopisto, maataloustieteiden laitos, PL 28 (Koetilantie 5), 00014 Helsingin yliopisto, han- \\ na-riitta.kymalainen@helsinki.fi
}

\section{TIIVISTELMÄ}

Onneksi työtapaturmien määrä maatiloilla on laskenut viime vuosina. Kuitenkin esimerkiksi vuonna 2013 työtapaturmasuhde maatalousyrittäjillä oli yli 2,5-kertainen palkansaajiin verrattuna: maatalousyrittäjille sattui 4994 ja palkansaajille 1887 työtapaturmaa 100000 henkilöä kohti. Miltei puolet kaikista maatalousyrittäjien työtapaturmista tapahtui karjanhoitotöiden aikana. Luonnonvarakeskuksen (Luken) julkaisuun "Opas turvalliseen karjanhoitoon" on koottu lukuisista eri lähteistä tietoutta ja ohjeita työturvallisuuden lisäämiseksi karjatiloilla.

Kotieläimet, koneet, liukastumiset, putoamiset ja ylirasittuminen ovat yleisimpiä tapaturmiin liittyviä tekijöitä. Oppaan alussa kerrotaan, miten turvallisuutta lisätään eläinten hoitotyön aikana. Seuraavaksi esitetään keinoja liukastumisten ja putoamisten ehkäisemiseksi sekä annetaan ohjeita kotieläintilan erilaisten koneiden turvallisesta käytöstä. Haitallista kuormittumista fyysisessä työssä torjutaan mm. oikealla nostotekniikalla. Työhyvinvointia edistetään annostelemalla kuormitusta kohtuudella. Oppaassa esitellään myös erilaisia selviytymistapoja elämän karikkovaiheisiin.

Kotieläintilan erityisiä vaaranpaikkoja ovat suljetut tilat eli esimerkiksi säiliöt, tankit ja siilot. Lietelannan sekoituksen ja liikuttelun aikana kaasujen määrät ja pitoisuudet voivat kohota nopeasti vaarallisiin lukemiin. Lietesäiliöön menevä varustetaan turvavaljailla sekä pelastusköydellä ja säiliön ulkopuolella pitää olla aina varmistushenkilö seuraamassa tilannetta. Puhtaan hengitysilman takaa raitisilmalaite tai paineilmasäiliölaite. Vakavia onnettomuuksia on tapahtunut mm. traktoreilla, joissa ei ole turvaohjaamoa tai suojakaarta. Jos traktori syystä tai toisesta kierähtää ympäri, ohjaaja on todellisessa vaarassa. Viime vuosina myös etukuormaajaan kiinnitetyn kauhan tai paalipihtien putoaminen tai kauhan maakosketus on aiheuttanut onnettomuuksia. Jotta onnettomuuksilta vältyttäisiin, tulisi etukuormaajan kiinnitykset tarkistaa, ajonopeuden tulisi olla kuljetuksen aikana kohtuullinen ja ohjaajan kannattaa käyttää turvavyötä.

Kotieläinrakennuksen sisäilma saattaa sisältää seoksen pölyjä, rikkivetyä ja ammoniakkia. Niiden yhteisvaikutus voi lisätä pölyn terveydelle haitallisia terveysvaikutuksia 2-4-kertaisiksi. Jos rehua tai kuiviketta jaetaan eläimille käsin, käytetään vähintään P2-luokan suodattimella varustettua hengityksensuojainta, joka asettuu kasvoille tiiviisti.

Zoonoosien eli eläimistä ihmiseen siirtyvien tautien oireet voivat olla vaihtelevia ja hankalasti tunnistettavia. Ilmastonmuutos saattaa lisätä zoonoosien esiintyvyyttä. Kotieläinten hoitajan kannattaa olla zoonoosien osalta valppaana, vaalia kotieläintilan tautisulkua ja huolehtia henkilökohtaisesta suojautumisesta sekä hygieniasta. Opas sisältää tekstikokonaisuudet myös sähköturvallisuudesta, melun torjunnasta ja hätäensiavun antamisesta.

Tehokkainta turvallisuuden vaalimista on altisteen poistaminen esimerkiksi valitsemalla mahdollisimman turvallinen kemikaali. Koneita ja laitteita voidaan hyödyntää fyysisen rasituksen vähentämiseksi esimerkiksi raskaiden taakkojen siirrossa. Kolmantena keinona on henkilökohtainen suojautuminen ja neljäntenä turvallisuusosaamisen ylläpitäminen. Kehitä itsellesi turvallisuutta arvioiva katse!

Opas on sähköisessä muodossa saatavilla osoitteessa http://jukuri.luke.fi/ handle/10024/486090. Oppaan sisältöä koskevaa palautetta voi lähettää sähköpostiosoitteeseen karjaturva@luke.fi

Asiasanat: karjanhoito, neuvonta, opas, työtapaturma, työturvallisuus 


\section{Johdanto}

Työturvallisuuden vaaliminen maataloudessa on haasteellinen tehtävä, sillä työolosuhteet vaihtelevat, ja erilaisia työvaiheita on runsaasti. Menetelmät, käytettävät koneet sekä laitteet osin vaihtuvat vuodenaikojen mukaan. Korjuukauden aikana toimitaan sääolosuhteiden sallimissa puitteissa, mikä voi lisätä kiirettä ja aikapaineita. Maatalousyrittäjä työskentelee usein yksin. Toisinaan maatilan töissä puurtaa ikääntynyt henkilö, ja väliin koneen ohjaimissa on viljelijäperheen nuorison edustaja. Viljelijä vastaa yrittäjien tapaan työympäristönsä turvallisuudesta itse, joskin työterveyshuolto voi tarjota tässä tehtävässä asiantuntevaa tukea ja apua.

Työtapaturmien määrä maatiloilla on viime vuosina ollut onneksi laskussa maatalousyrittäjien määrään suhteutettuna. Silti maatalous on edelleen yksi vaarallisimmista työaloista Suomessa. Vuonna 2013 maatalousyrittäjille sattui 4994 tapaturmaa 100000 vakuutettua kohti, kun vastaava lukema palkansaajilla oli huomattavasti pienempi, 1 887. Työkuolemia puolestaan tapahtui vuonna 2012 maatalousyrittäjillä 9,4 sataatuhatta vakuutettua kohti ja palkansaajilla vain 1,5. Vuonna 2012 kuolemaan johtaneita tapaturmia oli maatiloilla seitsemän ja vuonna 2013 neljä. Vuonna 2013 kaikista maatalouden työtapaturmista $43 \%$ tapahtui karjanhoitotöiden aikana. Yli neljänneksessä (26 \%) työtapaturmissa vamman välitön aiheuttaja oli eläin, ihminen tai kasvi. Oletettavasti eläimet ovat tässä ryhmässä yleisin tapaturman aiheuttaja (Suomen virallinen tilasto, 2014; Suomen virallinen tilasto, 2015).

\section{Oppaan kokoaminen}

Oppaan kirjoittamisen taustana olivat kaksi aiemmin julkaistua artikkelia:

Kallioniemi M. K., Raussi S. M., Rautiainen R. H. \& Kymäläinen H.-R. 2011. Safety and Animal Handling Practices among Women Dairy Operators. Journal of Agricultural Safety and Health 17(1): 63-78.

Kallioniemi M. K., Simola A., Kinnunen B. \& Kymäläinen H.-R. 2011. Stress in farm entrepreneurs. In: Langan-Fox J. and Cooper C. L. (Eds.) Handbook of Stress in the Occupations. pp. 385-406. Cheltenham, UK and Northampton, MA, USA: Edward Elgar.

Lisäksi oppaan kirjoittajalle (Marja Kallioniemi) tarjoutui mahdollisuus osallistua Iowan yliopistolla, USA:ssa järjestettyyn kurssiin "Agricultural Medicine" 9.-13.6.2014. Yhteistyö ja tietojen vaihto väitöskirjan esitarkastajan professori Deborah Reedin (Kentuckyn yliopisto, USA) kanssa johdatteli osaltaan oppaan kirjoittamista.

Opashanke sai taloudellista tukea Mela työturvallisuusapurahoista sekä MTT:n strategisen suuntaamisen rahoituksesta. Parhaimmat kiitokset hankkeen rahoittajille.

Opaskäsikirjoitusta kommentoi ryhmä eri alojen asiantuntijoita. Palaute auttoi rakentamaan oppaan sisältöä mahdollisimman hyvin viljelijää palvelevaksi. Tekstin tavoitteeksi asetettiin hyödyllisen sisällön lisäksi muun muassa ytimekäs ilmaisu, jota on tehostettu luetteloiden ja väliotsikoiden avulla. Oppaan sisältöä kommentoivat seuraavat henkilöt: Marita Bjøru, maatalousyrittäjä, kätilö; Erik Lindroos, työturvallisuusagronomi, Maatalousyrittäjien eläkelaitos, Mela; Riitta Lehtinen, projektipäällikkö, Hämeen ammattikorkeakoulu, Mustiala; Hanna-Riitta Kymäläinen, dosentti, yliopistonlehtori, maataloustieteiden laitos, Helsingin yliopisto; Kari Maunula, tarkastaja, Luonnonvarakeskus, Vihreä teknologia (tekstiosuus "Turvallisesti kotieläintilan koneilla"); Kristiina Myllyrinne, asiantuntija, terveys ja ensiapu, Suomen Punainen Risti (tekstiosuus "Onnettomuuden sattuessa eli hätäensiavun ABC"); Leila Mäkelä, tuotantoneuvoja, Länsi-Maito; Tuija Mäntylä, maatalousyrittäjä; Sami Myyrä, professori, Luonnonvarakeskus (Luke), Talous ja yhteiskunta; Anna-Riikka Pukari, asiantuntija, Maatalousyrittäjien eläkelaitos, Mela; Satu Raussi, johtaja, Eläinten Hyvinvointikeskus, Helsingin yliopisto; Deborah Reed, professori, Kentuckyn yliopisto ja Southeast Center for Agricultural Health and Injury Prevention, USA; Ari Ronkainen, tutkija, Luonnonvarakeskus, Vihreä teknologia (tekstiosuus "Turvallisesti kotieläintilan koneilla") ja Silja Suni, lääketieteen kandidaatti, Helsingin yliopisto (tekstiosuus "Onnettomuuden sattuessa eli hätäensiavun $\mathrm{ABC}$ "). Oppaan kuvamateriaalia kerättiin hankkeen tilakäynneiltä ja MTT:n arkistosta. Lisäksi puuttuvia kuvia saatiin Melasta ja Suomen Punaisesta Rististä. Haluamme kiittää kaikkia oppaan tekemisessä auttanutta ja tukenutta henkilöä sekä organisaatiota.

Opas julkaistiin Luonnonvarakeskuksen internet-sivuilla 28.5.2015. Opas on kokonaisuudessaan saatavilla ja tulostettavissa osoitteessa: http://urn.fi/URN:ISBN:978-952-326-042-9. Marraskuun 2015 puoleen väliin mennessä julkaisutiedosto oli avattu miltei 700 kertaa. Painetun oppaan voi tilata 
osoitteessa http://luke.juvenesprint.fi/fi/. Julkaisun hinta on $48 €$, toimituskulut $9 €$, jolloin painetun oppaan tilaaminen maksaa yhteensä 57 euroa.

\section{Oppaan sisältö}

Kotieläimet, koneet, liukastumiset, putoamiset ja ylirasittuminen ovat yleisimpiä tapaturmiin liittyviä tekijöitä. Oppaan alussa kerrotaan, miten turvallisuutta lisätään eläinten hoitotyön aikana. Karjanhoitajan kannattaa olla erityisen varuillaan, kun hoidettava eläin on kiimassa, tuntee kipua, sairastaa, pelkää, on loukkaantunut tai erotettu omasta ryhmästään. Myös juuri poikinut, jälkeläistään suojeleva eläin voi yllättäen hyökätä hoitajaa kohti. Ryhmän ylempiarvoisempaa eläintä väistävä yksilö voi töytäistä pienemmän esteen eli hoitajan pois tieltään. Omien hoidettavien eläinten tunteminen yksilöinä auttaa ennakoimaan ja välttämään vaarallisia tilanteita. Hoitajalla on hyvä olla aina jotain kättä pidempää mukana, kun hän liikkuu eläinten joukossa. (Grandin, 1999; Raussi, 2003; Jahkola, 2005; Grandin \& Deesing, 2008; Jahkola, 2013)

Oppaassa käsitellään myös keinoja liukastumisten ja putoamisten ehkäisemiseksi sekä annetaan ohjeita kotieläintilan erilaisten koneiden turvallisesta käytöstä. Koneiden ja laitteiden säännöllinen kunnossapito ehkäisee tapaturmia. Koneiden säätämisen, tukkeuman poiston tai puhdistamisen aikana kannattaa olla erityisen varuillaan. Automatisoidun laitteiston odottamaton käynnistyminen tai robotin liikkuminen ovat yleisimmät automaatiojärjestelmiin liittyvät tapaturman aiheuttajat. Laitteiston virta tulee kytkeä aina pois ennen huoltotoimenpiteitä. Vakavia onnettomuuksia on tapahtunut mm. traktoreilla, joissa ei ole turvaohjaamoa tai suojakaarta. Jos traktori syystä tai toisesta kierähtää ympäri, ohjaaja on todellisessa vaarassa. Viime vuosina myös etukuormaajaan kiinnitetyn kauhan tai paalipihtien putoaminen tai kauhan maakosketus on aiheuttanut onnettomuuksia. Jotta onnettomuuksilta vältyttäisiin, tulisi etukuormaajan kiinnitykset tarkistaa, ajonopeuden tulisi olla kuljetuksen aikana kohtuullinen ja ohjaajan kannattaa käyttää turvavyötä. (Malm toim., 2008; Kiviranta, 2013; Deenan, 2014; Puustinen, 2014; Rohlman, 2014)

Fyysisistä kuormitustekijöistä oppaassa käsitellään haitallista kuormittumista fyysisessä työssä. Työhyvinvoinnin osalta käydään läpi, millaisia elementtejä työhyvinvointiin sisältyy. Riittävä yöuni, terveellinen ruoka, fyysinen kunto, arjen sujuvuus ja selkeät tavoitteet, mukavat ihmissuhteet, onnistuneet lomat sekä oma ammattitaito ovat kaikki työhyvinvointiin sisältyviä osia. Oppaassa esitellään myös erilaisia selviytymistapoja elämän karikkovaiheisiin. (Heiskanen et al., 2006; Jabe, 2010; Räisänen, 2012)

Kotieläintilan erityisiä vaaran paikkoja ovat suljetut tilat eli esimerkiksi säiliöt, tankit ja siilot. Lietelannan sekoituksen ja liikuttelun aikana kaasujen määrät ja pitoisuudet voivat kohota nopeasti vaarallisiin lukemiin. Lietesäiliöön menevä varustetaan turvavaljailla sekä pelastusköydellä ja säiliön ulkopuolella pitää olla aina varmistushenkilö seuraamassa tilannetta. Puhtaan hengitysilman takaa raitisilmalaite tai paineilmasäiliölaite. (Eskola, 2011; Mela, 2012; Merjama, 2012; Louhelainen, 2013)

Kotieläinrakennuksen sisäilma saattaa sisältää seoksen pölyjä, rikkivetyä ja ammoniakkia. Niiden yhteisvaikutus voi lisätä pölyn terveydelle haitallisia terveysvaikutuksia 2-4-kertaisiksi. Jos rehua tai kuiviketta jaetaan eläimille käsin, käytetään vähintään P2-luokan suodattimella varustettua hengityksensuojainta, joka asettuu kasvoille tiiviisti. (Lahin, 2000; Jääskeläinen, 2006; Gerr, 2014; Louhelainen \& Mäittälä, 2014; Mela, 2014)

Zoonoosien eli eläimistä ihmiseen siirtyvien tautien oireet voivat olla vaihtelevia ja hankalasti tunnistettavia. Ilmastonmuutos saattaa lisätä zoonoosien esiintyvyyttä. Kotieläinten hoitajan kannattaa olla zoonoosien osalta valppaana, vaalia kotieläintilan tautisulkua ja huolehtia henkilökohtaisesta suojautumisesta sekä hygieniasta (Bickett-Weddle, 2014; Leedom, 2014; Sihvonen, 2012; Zoonoosikeskus, 2012). Opas sisältää tekstikokonaisuudet myös sähköturvallisuudesta, melun torjunnasta ja hätäensiavun antamisesta.

Tehokkainta turvallisuuden vaalimista on altisteen poistaminen esimerkiksi valitsemalla mahdollisimman turvallinen kemikaali. Koneita ja laitteita voidaan hyödyntää fyysisen rasituksen vähentämiseksi esimerkiksi raskaiden taakkojen siirrossa. Kolmantena keinona on henkilökohtainen suojautuminen ja neljäntenä turvallisuusosaamisen ylläpitäminen. (Rohlman, 2014)

Oppaassa on monia yksityiskohtaisia neuvoja maatilan turvallisuuden edistämiseksi. Yleisenä toimintaperiaatteena tai -ohjeena voisi olla: "Kehitä itsellesi turvallisuutta arvioiva katse!" Oppaan sisältö kokonaisuudessaan ilmenee Taulukosta 1. 
Taulukko 1. Maatalouden työympäristön vaarat ja kuormitustekijät, esimerkkejä niistä sekä "Opas turvalliseen karjanhoitoon" -julkaisun sisältö.

\begin{tabular}{|c|c|c|}
\hline $\begin{array}{l}\text { Vaarat ja kuormituste- } \\
\text { kijät }\end{array}$ & Esimerkkejä & Oppaan sisältö \\
\hline TAPATURMAVAARAT & $\begin{array}{l}\text { Liukastuminen, kompas- } \\
\text { tuminen, esineisiin tör- } \\
\text { määminen, takertuminen }\end{array}$ & $\begin{array}{l}\text { Luku 2. } \\
\text { Turvallisuus eläinten hoitotyössä } \\
\text { Älä liukastu tai putoa } \\
\text { Turvallisesti kotieläintilan koneilla } \\
\text { Varo työskentelyä suljetussa tilassa } \\
\text { Siisteys ja järjestys edistävät työturvallisuutta }\end{array}$ \\
\hline FYYSISET & $\begin{array}{l}\text { Kulumat, nivelsäryt, } \\
\text { selkäkipu }\end{array}$ & $\begin{array}{l}\text { Luku 3. } \\
\text { Haitallinen kuormittuminen fyysisessä työssä }\end{array}$ \\
\hline FYSIKAALISET & $\begin{array}{l}\text { Melu, tärinä, kuumuus, } \\
\text { kylmyys, puutteellinen } \\
\text { valaistus }\end{array}$ & $\begin{array}{l}\text { Luku } 4 . \\
\text { Kotieläinrakennukseen toimiva ilmanvaihto } \\
\text { Vaimenna työympäristön melu } \\
\text { Sähköturvallisuus } \\
\text { Työ kuumassa ja kylmässä }\end{array}$ \\
\hline $\begin{array}{l}\text { KEMIALLISET JA } \\
\text { BIOLOGISET }\end{array}$ & $\begin{array}{l}\text { Torjunta-aineet, pesuai- } \\
\text { neet, liuottimet, baktee- } \\
\text { rit, virukset ja punkit }\end{array}$ & $\begin{array}{l}\text { Luku } 5 . \\
\text { Kemikaaliturvallisuus } \\
\text { Eläimistä ihmiseen siirtyvät taudit - zoonoosit }\end{array}$ \\
\hline HENKISET & $\begin{array}{l}\text { Stressi, uupuminen, } \\
\text { ahdistuminen }\end{array}$ & $\begin{array}{l}\text { Luku } 6 . \\
\text { Miten vaalin työhyvinvointia? } \\
\text { Kuormitusta kohtuudella } \\
\text { Miten tunnistan uupumisen? } \\
\text { Selviytymistavoissa on vara valita! }\end{array}$ \\
\hline OHJEITA & $\begin{array}{l}\text { Suojaimet, työvaatteet, } \\
\text { ensiapu }\end{array}$ & $\begin{array}{l}\text { Luku } 7 . \\
\text { Raskausajan riskit kotieläintilalla } \\
\text { Suojaa lapset ja nuoret onnettomuuksilta } \\
\text { Suurehkon maatilan pelastus- ja turvallisuus- } \\
\text { suunnitelma } \\
\text { Henkilönsuojaimet } \\
\text { Työvaatteet } \\
\text { Kun kotieläintilalle palkataan työntekijä } \\
\text { Onnettomuuden sattuessa eli hätäensiavun } \\
\text { ABC }\end{array}$ \\
\hline
\end{tabular}

\section{Johtopäätökset}

Opas turvalliseen karjanhoitoon valmistui toukokuussa 2015. Oppaaseen on koottu lukuisista eri lähteistä tietoutta ja ohjeita työturvallisuuden lisäämiseksi karjatiloilla. Erilaisista lähteistä ja internetistä löytyy paljon kotieläintilojen turvallisuuteen liittyvää hyödyllistä tietoa, mutta aineistot ovat kuitenkin kovin hajallaan. Oppaan ideana on ollut koota yksien kansien väliin tietopaketti turvallisesta karjanhoidosta. Toivottavasti julkaistu opas auttaa vaalimaan työturvallisuutta ja työhyvinvointia kotieläintiloilla. Turvallista kotieläinten hoidon arkea!

Kirjallisuus

Bickett-Weddle, D. 2014. Zoonotic Diseases. Rural Health and Agricultural Medicine. Esitelmäkalvot kurssilla "Agricultural Medicine", 9.-13.6.-2014. University of Iowa, Iowa's Center for Agricultural Safety and Health \& Rural Health and Safety Clinic. USA.

Deenan, D. 2014. Agricultural trauma. Esitelmäkalvot kurssilla “Agricultural Medicine”, 9.-13.6.-2014. Univer- 
sity of Iowa, Iowa's Center for Agricultural Safety and Health \& Rural Health and Safety Clinic. USA. Eskola, E. 2011. Vaara vaanii säilörehusiilossa. Maito ja me 23:2, s.24. Helsinki: Maataloustuottajain palvelu. Gerr, F. 2014. Occupational diseases of the Lungs in Agricultural Settings. Esitelmäkalvot kurssilla "Agricultural Medicine", 9.-13.6.-2014. University of Iowa, Iowa's Center for Agricultural Safety and Health \& Rural Health and Safety Clinic. USA.

Grandin, T. 1999. Safe handling of large animals. State of the Art Reviews. Occupational Medicine, 14(2): 195212.

Grandin, T. \& Deesing, M. 2008. Humane livestock handling. Understanding livestock behavior and building facilities for healthier animals. 227 s. Storey Publishing: North Adams, MA, USA.

Heiskanen, T., Salonen, K. \& Sassi, P. 2006. Mielenterveyden ensiapukirja. Suomen Mielenterveysseura, SMS-Tuotanto Oy.

Jabe, M. 2010. Voitko hyvin työssäsi? Opas alaiselle ja esimiehelle. Yrityskirjat.

Jahkola, J. 2005. Johdatus nautaeläinten käsittelyyn. 84 s. Turku. LSO Foods.

Jahkola, J. 2013. Laidunsiirrot ja eläinten käsittely. 10 s. Hanke: Rotukarjan hyvinvoinnin ja taloudellisten toimintaedellytysten kehittäminen. Manner-Suomen maaseudun kehittämisohjelma.

Jääskeläinen, V. 2006. Pölyt ja kaasut pois hengitysilmasta. Valitse oikein hengityssuojain. s. 14-17. Lihatalous 2/2006.

Kiviranta, T. 2013. Turvavöitä vaaditaan myös traktoreihin. Maaseudun Tulevaisuus 18.9.2013.

Lahin, P. 2000. Henkilönsuojainten käyttö maatalouslomitustiloilla. Teho 2(2000), s. 16-17.

Leedom, K. 2014. Zoonootic Diseases. Esitelmäkalvot kurssilla "Agricultural Medicine", 9.-13.6.-2014. University of Iowa, Iowa's Center for Agricultural Safety and Health \& Rural Health and Safety Clinic. USA. Louhelainen, K. 2013. Kemialliset vaaratekijät ja niiden hallinta. Teoksessa: Suurnäkki, T. (toim.) Maatalouslomittajan työturvallisuus ja työhyvinvointi. Kuntaryhmä ja maatalousalojen työalatoimikunta. Työturvallisuuskeskus.

Louhelainen, K. \& Mäittälä, J. 2014. Henkilönsuojainten valinta ja käyttö. Teoksessa: Suurnäkki, T. (toim.) Maatalouslomittajan työturvallisuus ja työhyvinvointi. Kuntaryhmä ja maatalousalojen työalatoimikunta. Työturvallisuuskeskus.

Malm, T. (toim.) 2008. Vuorovaikutteisen robotiikan turvallisuus. VTT, Tampereen teknillinen yliopisto, Tuotantotekniikka, Suomen Robotiikkayhdistys ry. Helsinki.

Mela, 2012. Lietelanta voi tappaa. Turvallisesti työssä -esite. 8 s. Maatalousyrittäjien eläkelaitos. Mela 2014. Suojaa itsesi. 16 s. Turvallisesti työssä -esite.

Merjama, J. 2012. Työskentely säiliöissä ja suljetuissa tiloissa. 2. painos. 16 s. Työturvallisuuskeskus TKK. Raussi, S. 2003. Human-cattle interactions in group housing. Applied Animal Behaviour Science, 80(3): 245262.

Rohlman, D. 2014. Prevention of Agricultural Injuries and Illnesses. Esitelmäkalvot kurssilla "Agricultural Medicine”, 9.-13.6.-2014. University of Iowa, Iowa's Center for Agricultural Safety and Health \& Rural Health and Safety Clinic. USA.

Räisänen, K. 2012. Työstressirokotus. Työterveyslaitos.

Sihvonen, T. 2012. Tarttuvilta eläintaudeilta suojautuminen. Tilaesimerkkinä Ilmajoen koulutilan navetta ja sikala. Opinnäytetyö. Maa- ja metsätalouden koulutusyksikkö. Maaseutuelinkeinojen koulutusohjelma. Seinäjoen ammattikorkeakoulu.

Suomen virallinen tilasto, 2014. Työtapaturmat 2012. Helsinki: Tilastokeskus. Viitattu: 9.12.2015. Saatavilla: http://tilastokeskus.fi/til/ttap/2012/ttap_2012_2014-11-28_fi.pdf

Suomen virallinen tilasto, 2015. Työtapaturmat 2013. Helsinki: Tilastokeskus. Viitattu: 9.12.2015. Saatavilla: http://www.stat.fi/til/ttap/2013/ttap_2013_2015-11-27_tie_001_fi.html

Puustinen, J. 2014. Maatilan kone- ja sähköturvallisuus. Teoksessa: Suurnäkki, T. (toim.) Maatalouslomittajan työturvallisuus ja työhyvinvointi. Kuntaryhmä ja maatalousalojen työalatoimikunta. Työturvallisuuskeskus TKK.

Zoonoosikeskus 2012. Zoonoosit Suomessa 2000-2010. 88 s. 2. uudistettu painos. Evira, Terveyden ja Hyvinvoinnin laitos, Zoonoosikeskus. 